\title{
Exotic ornamental fishes in Iranian inland water basins: an updated checklist
}

\author{
Hamed Mousavi-Sabet \\ Department of Fisheries, Faculty of Natural Resources, University of Guilan, Sowmeh Sara, Iran \\ Corresponding author $\bowtie$ : mousavi-sabet@guilan.ac.ir
}

\begin{abstract}
The number of exotic freshwater ornamental fish species released from the aquarium trade in Iran has been increasing in recent years. All

Received: 30 March 2019 Accepted: 13 July 2019

Published online: 30 September 2019 recorded exotic aquarium fishes are listed here, including 8 species in 7 genera, 5 families, and 5 orders. The introduced species belong to the Neotropical, Nearctic and Palearctic fish elements. Their distribution ranges within Iranian freshwater ecosystems are given, and the presence of Koi (ornamental Cyprinus carpio) are recorded for the first time from Iranian inland waters. Eradication programs need to be accompanied by a public awareness campaign to ensure that the aquarium trade and hobbyists do not release these pet fishes into natural habitats.
\end{abstract}

Key words: Aquarium trade, exotic fish, alien species, Neotropical, Nearctic, Palearctic

\section{Introduction}

The introduction of nonnative fish species to Iran has increased considerably within recent decades (Jouladeh-Roudbar et al., 2015), reaching 29 confirmed species belonging to eleven families for Iran (Esmaeili et al., 2018). Development of the aquarium trade industry, increasing transport capacity and economic globalization have accelerated the rate of introductions of alien species throughout the world. Therefore, one of the important pathways for the introduction of non-indigenous species is the aquarium fish trade (Copp et al., 2005; Rixon et al., 2005; Nunes et al., 2015), and several freshwater ornamental fish species have been reported within the last few years in Iran (Esmaeili et al., 2013; Mousavi-Sabet and Eagderi, 2014; 2016; Esmaeili et al., 2017). Introductions of fish species into Iranian water bodies dates back a long time, but were most prominent in the 1920s when the mosquitofish, Gambusia holbrooki Girard, 1859 (Poeciliidae) was introduced as an anti-malarial agent (Esmaeili et al., 2010; Jouladeh-Roudbar et al., 2015). Since then, about 9.76\% of the Iranian ichthyofauna has comprised of introduced fishes (Esmaeili et al., 2018). Aquaculture, the aquarium trade, sport fishing, control of malaria, research and accidental introductions have been the main reasons for these introductions in the country (Coad, 1996; Esmaeili et al., 2007; Radkhah et al., 2016).

In this paper, the exotic ornamental fishes within Iranian freshwater ecosystems are listed, their distributions are given, and approaches to future research and management strategies are suggested. 


\section{Material and Methods}

The current checklist is based on information collected from extensive searches of databases including the Zoological Record, Catalog of Fishes, Fishbase, Biological Abstracts, Helminthological Abstracts, Web of Knowledge, Google Scholar, Aquatic Sciences and Fisheries Abstracts Bibliography, and extensive field expeditions since 2008 throughout Iran. The fishes were collected from different water bodies, using different equipment, such as hand-net, gillnet, and electrofishing equipment. After anaesthesia, fishes were fixed in 5\% formaldehyde and stored in $70 \%$ ethanol or directly fixed in $99 \%$ ethanol. The collected specimens were deposited in the Vatandoust and Mousavi-Sabet Fish Collection, Tehran (VMFC). The presented map is prepared based on available records of the exotic ornamental fishes throughout Iranian water basins.

\section{Results}

The exotic ornamental fish species introduced to Iranian inland water basins are listed below and their distribution map is given in Figure 1. The alien fishes introduced to Iran due aquarium trade, comprise 8 species in 7 genera, 5 families, and 5 orders as follows:

\section{Taxonomic Account}

Order Characiformes Regan, 1911

Family Serrasalmidae Bleeker, 1859

Genus Piaractus Eigenmann, 1903

Piaractus brachypomus Cuvier, 1818 - Pirapitinga

Type locality: Brazil

Distribution in Iranian water basins: ehT Tigris River drainage, the Persian Gulf basin (Esmaeili et al., 2017) and also likely in the Hari River basin (Mousavi-Sabet et al., 2018).

Order Cichliformes Betancur-R et al., 2013

Family Cichlidae Bonaparte, 1835

Genus Amatitlania Schmitter-Soto, 2007

Amatitlania nigrofasciata (Günther, 1867) - Convict Cichlid (Fig. 2)

Type locality: Lake Amatitlán, Guatemala.

Distribution in Iranian water basins: Reported from headwater of the Kol River, Hormuz basin (Esmaeili et al., 2017) and the Soleymaniyeh spring, Namak Lake basin (Mousavi-Sabet and Eagderi, 2016).

Order Cypriniformes Bleeker, 1859

Family Cyprinidae Rafinesque, 1815

Genus Carassius Jarocki, 1822

Carassius auratus (Linnaeus, 1758) - Goldfish (Fig. 3)

Type locality: Cyprinus auratus Linnaeus, 1758 was originally described from China and Japanese rivers.

Distribution in Iranian water basins: Introduced to several basins in Iran.

Genus Cyprinus Linnaeus, 1758

Cyprinus carpio Linnaeus, 1758 - Koi (Fig. 4)

Type locality: Europe (for wild Cyprinus carpio).

Distribution in Iranian water basins: Introduced to the Sarcheshme Spring (335' $42.74^{\prime \prime} \mathrm{N}$, 50²6'59.57" E), Mahalat City, Markazi Province, Namak Lake basin. 


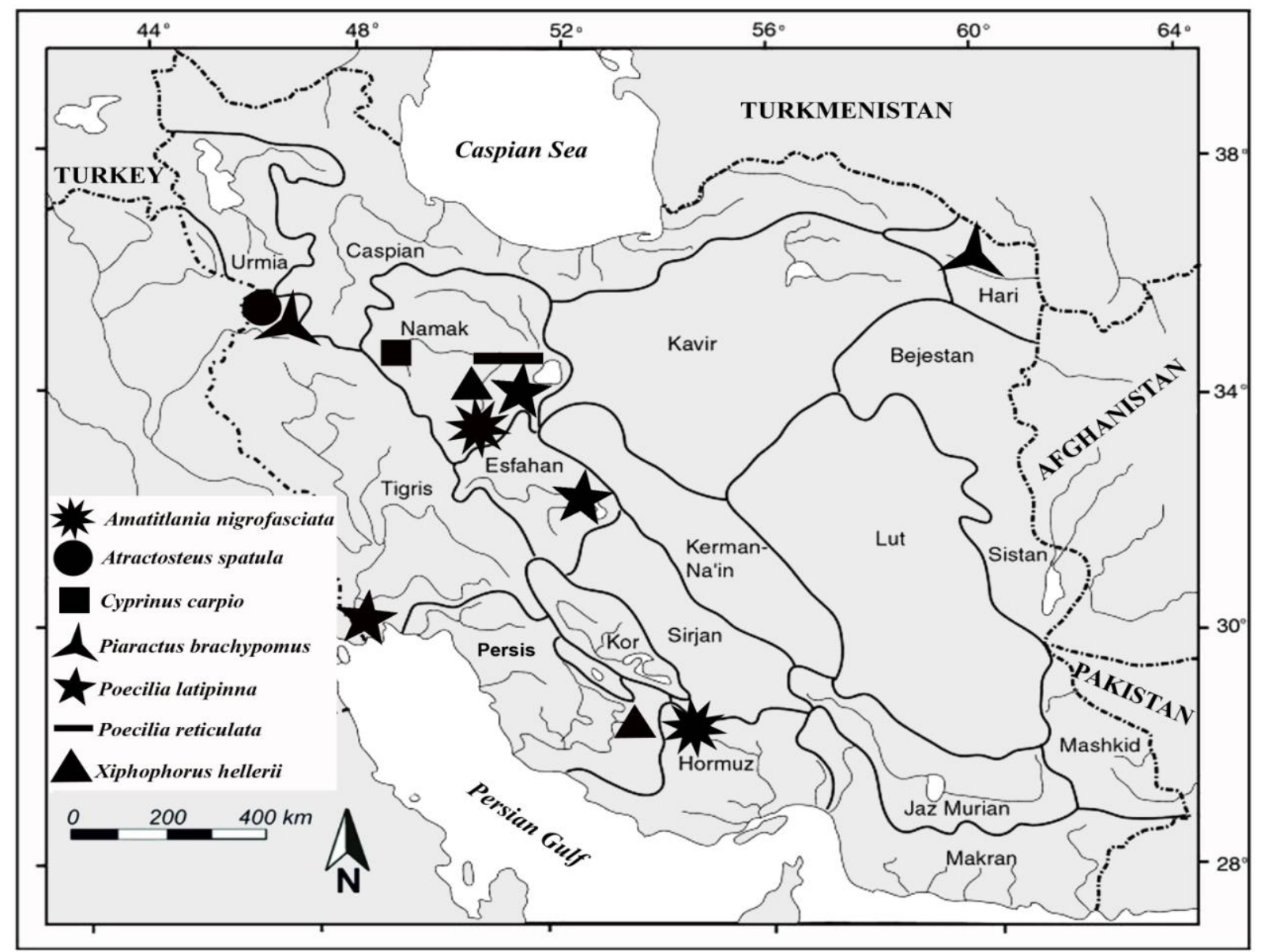

Figure 1: Map of the Iranian water basins, showing the distribution of 7 exotic ornamental fishes. The Goldfish, Carassius auratus, is ignored on the map, based on its wide distribution throughout Iran.

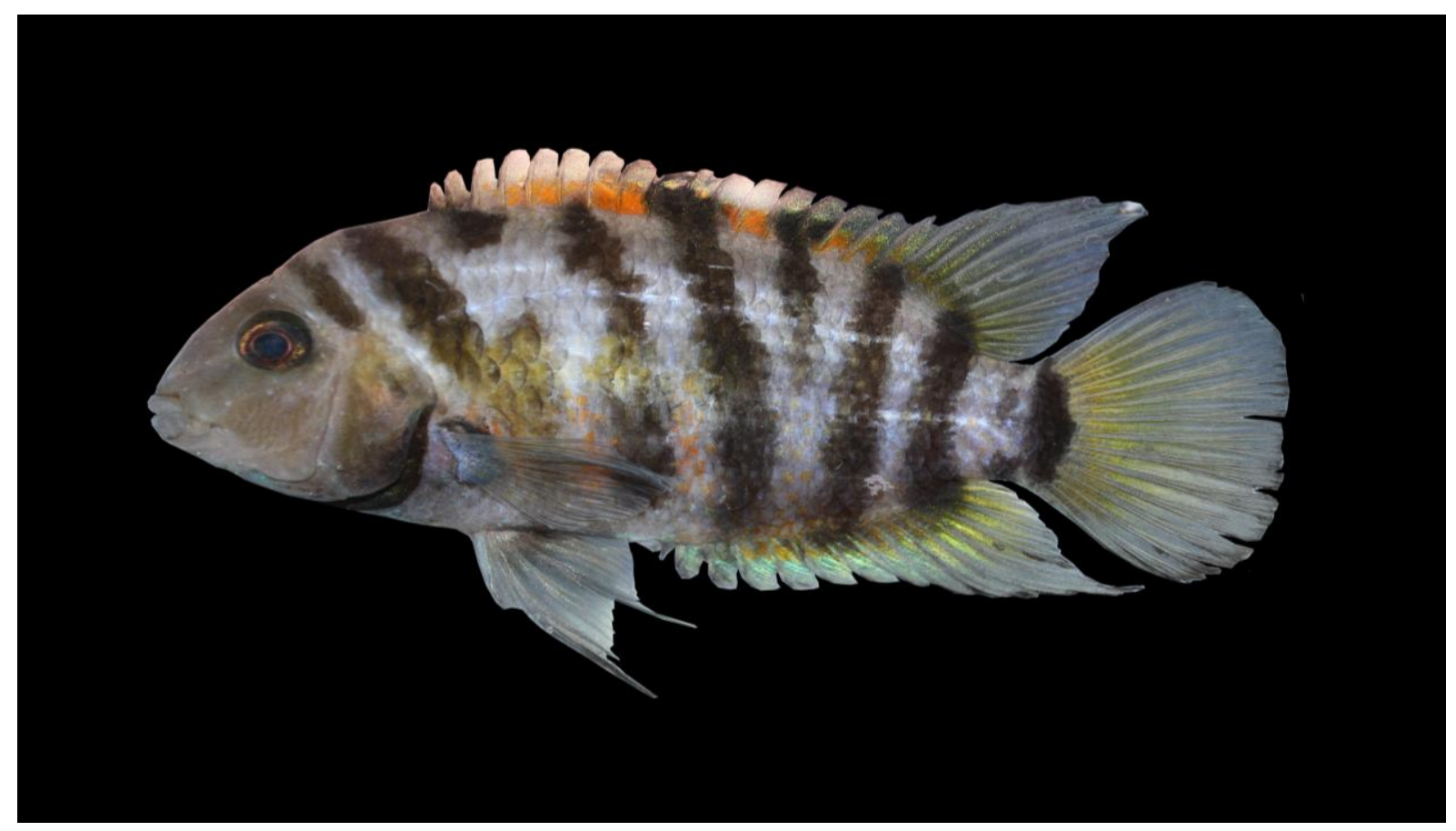

Figure 2: Amatitlania nigrofasciata: female, from the Namak Lake basin, Iran. 


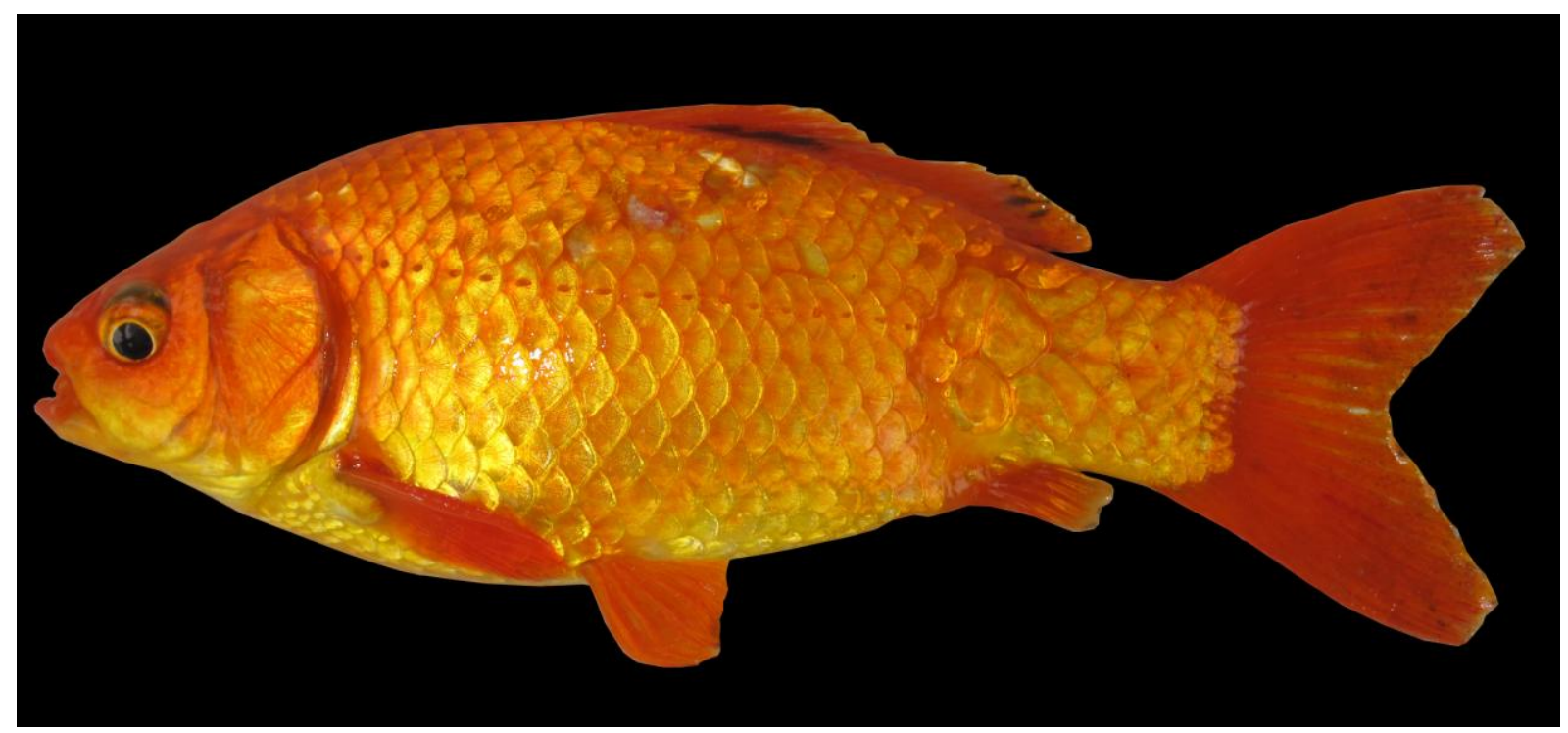

Figure 3: Carassius auratus, from the Tigris River basin, Iran.

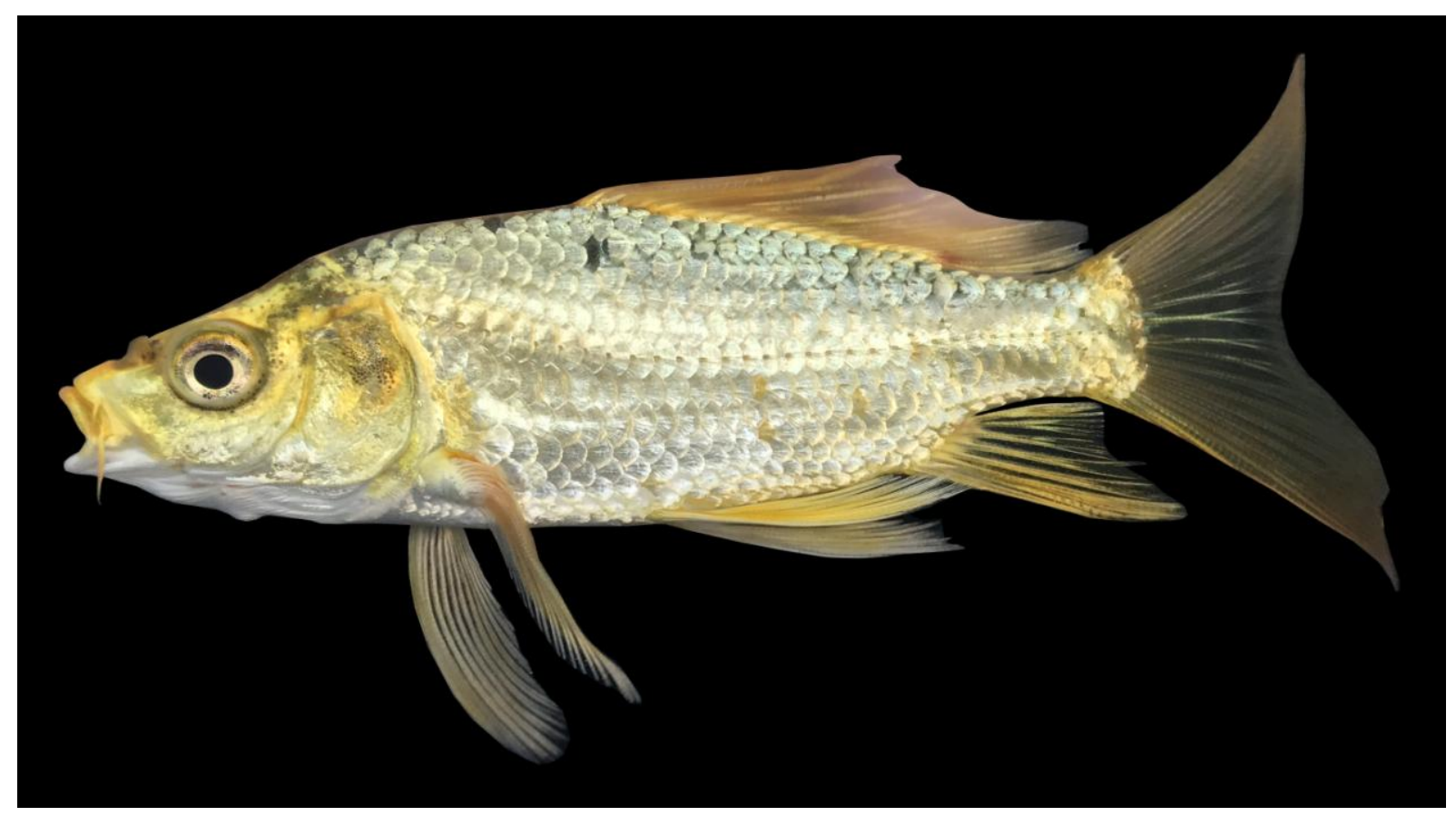

Figure 4: Cyprinus carpio, from the Namak Lake basin, Iran.

\section{Order Cyprinodontiformes Berg, 1940}

\section{Family Poeciliidae Garman, 1895}

\section{Genus Poecilia Bloch and Schneider, 1801}

Poecilia latipinna (Lesueur, 1821) - Sailfin Molly (Fig. 5)

Type locality: Freshwater ponds in the vicinity of New Orleans, Louisiana, USA.

Distribution in Iranian water basins: The Esfahan, Namak Lake and the Tigris River (Persian Gulf basin) basins (Esmaeili et al., 2017; Mousavi-Sabet, 2018).

Poecilia reticulata Peters, 1859 - Guppy (Fig. 6)

Type locality: The Guayre River, Caracas, Venezuela.

Distribution in Iranian water basins: The Namak Lake basin (Mousavi-Sabet and Eagderi, 2014). 


\section{Genus Xiphophorus Heckel, 1848}

Xiphophorus hellerii Heckel, 1848 - Green Swordtail (Fig. 7)

Type locality: Orizaba, Mexico [Atlantic].

Distribution in Iranian water basins: The Namak Lake and Persis basins.

Order Lepisosteiformes Hay, 1929

Family Lepisosteidae Cuvier, 1825

Genus Atractosteus Rafinesque, 1820

Atractosteus spatula (Lacepède, 1803) - Alligator gar

Type locality: North America.

Distribution in Iranian water basins: A single specimen of Atractosteus spatula was reported from the Marivan (Zarivar) Lake, in the Tigris River drainage, the Persian Gulf basin (Esmaeili et al., 2017).

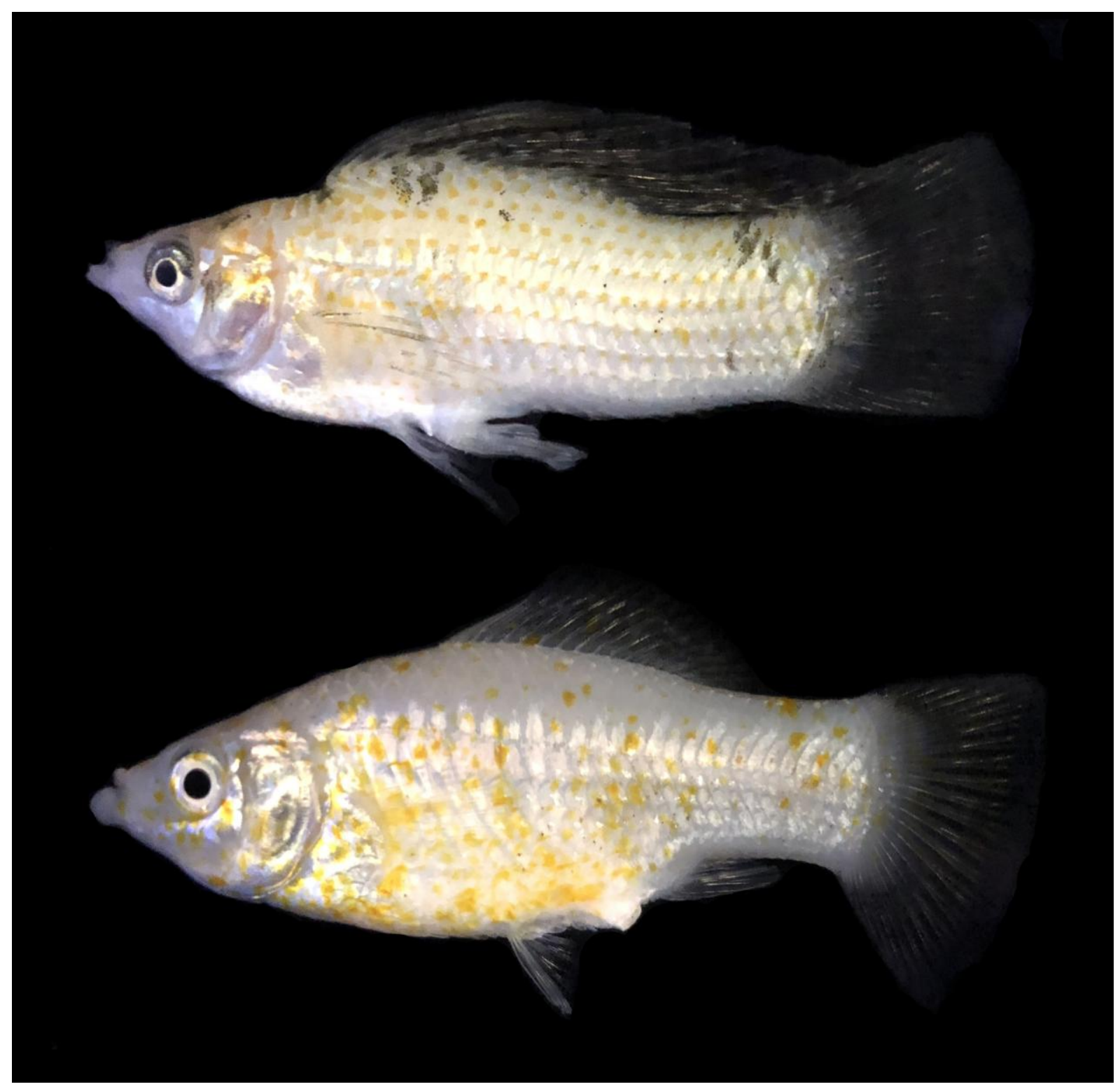

Figure 5: Poecilia latipinna: male (above) and female (below), from the Namak Lake basin, Iran. 


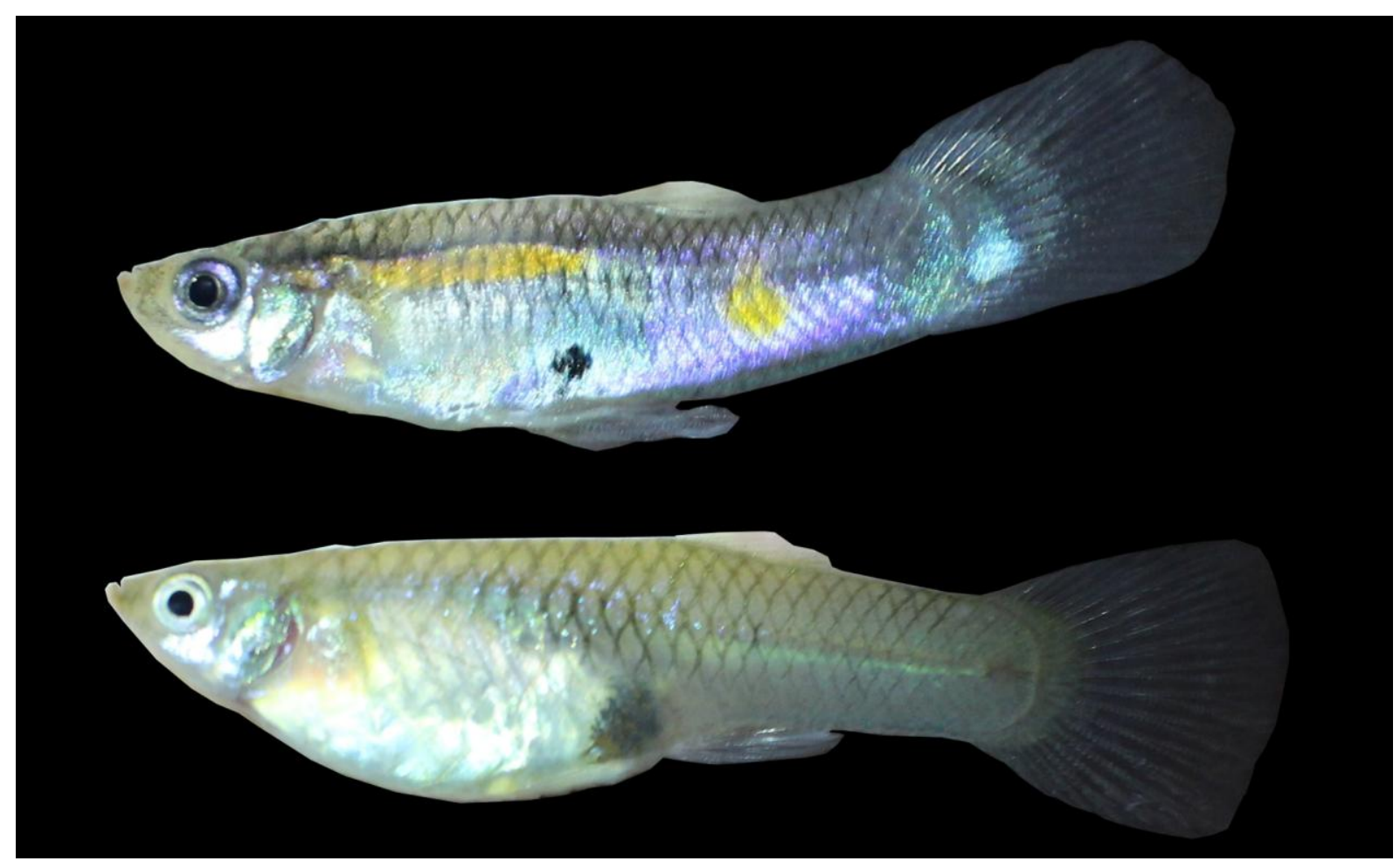

Figure 6: Poecilia reticulata: male (above) and female (below), from the Namak Lake basin, Iran.

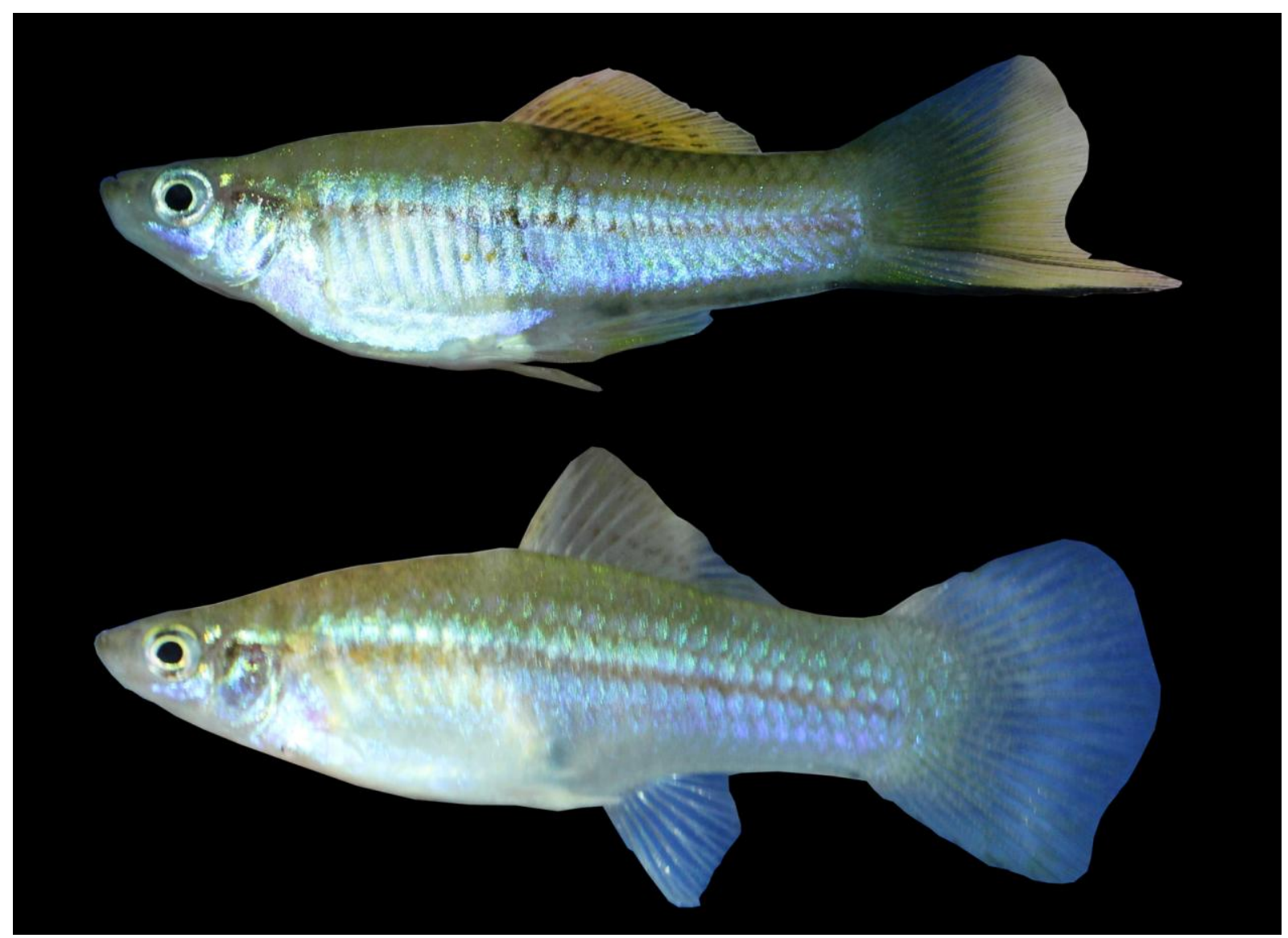

Figure 7: Xiphophorus hellerii: male (above) and female (below), from the Namak Lake basin, Iran. 


\section{Discussion}

Iran has been considered as one of the freshwater fish biodiversity hotspots in the Middle East with more than 268 native (including 95 endemic) fish species (Esmaeili et al., 2018). Similar to other world regions, the number of exotic fish species introduced in Iran is increasing in recent decades, reaching 29 confirmed species comprising about $9.76 \%$ of the total confirmed freshwater fishes in this country (Esmaeili et al., 2018). Aquaculture, the aquarium trade, sport fishing, control of malaria, research activities, demonstration in national fairs and accidental introduction are the main reasons for these introductions (Mousavi-Sabet and Eagderi, 2014; Mousavi-Sabet and Eagderi, 2016; Esmaeili et al., 2017; Mousavi-Sabet, 2018).

As listed above, the most diverse exotic species introduced to the Iranian water basins due to aquarium trade are members of the family Poeciliidae with three confirmed species. Livebearers are an important group of relatively small and often colorful aquarium fishes. Poeciliids are popular ornamental fishes in Iran and are also important as research models, being recently studied for ontogeny, growth, and sex reversal (Mousavi-Sabet and Ghasemnezhad, 2013; Faghani-Langroudi et al., 2014; Mousavi-Sabet et al., 2012, 2013, 2014, 2015; Moshayedi et al., 2015a; Moshayedi et al., 2015b; Khiabani et al., 2016). The family Poeciliidae (37 genera and about 304 species) includes live-bearing fishes of small size ( $<200 \mathrm{~mm}$ length) having the diverse morphology and coloration, with distribution in the freshwater and brackish environments of the eastern United States, South America, and Africa, including Madagascar (Moyle, 2002; Nelson, 2006). A myriad of poeciliids have been widely and deliberately introduced worldwide for mosquito control or the aquarium trade due to their short generation time, colorfulness, hardiness, and readiness to breed in captivity (Moyle, 2002).

The family Cyprinidae with two popular ornamental fishes is the second diverse family in the present checklist. The goldfish, Carassius auratus, is widely distributed throughout Iran due to its relationship to important Iranian traditions. The fish is one the main symbols in the Nowruz ceremony (Persian new year), and millions of the fish are bought for the Nowruz ceremony every year, and thousands of them released to natural water bodies by local people. Therefore, goldfish can be considered as the most distributed ornamental species in Iran. Despite the extended release, it is clear that goldfish cannot colonize in natural water bodies, as it is easy prey for predators. In addition, the mentioned variant of goldfish (related to Nowruz) is generally excluded from the aquarium trade, as no aquarist keeps the fish in aquaria and it is just a special ornamental fish for a single celebration (once a year). There are many other goldfish varieties in the aquarium trade in Iran, which are different from the "Nowruz goldfish".

The second exotic ornamental cyprinid in Iran, which is reported here for the first time, is the Koi (Cyprinus carpio). The presence of Koi in Iranian waters is observed for the first time in the Sarcheshme Spring, Sarcheshme Park, in Mahalat City, Markazi Province, where it was introduced by the Mahalat municipality for tourism purposes.

The families Lepisosteidae, Serrasalmidae and Cichlidae, each have only one member in the present checklist. It seems Atractosteus spatula and Piaractus brachypomus cannot sustain established populations in Iranian water basins yet because they seem to arrive episodically, and in few numbers. In contrast, Amatitlania nigrofasciata already produces established breeding populations.

It is well known that ornamental fishes are sold in pet shops and kept in aquaria all over the world, including Iran. It is also known that aquarists frequently get rid of unwanted/oversize 
fish by releasing them into natural water bodies. Ornamental species, like the other introduced species, may cause harm to native fishes. As the introduction of exotic fishes may affect populations of native fishes through predation, competition, habitat changes, genetic changes, and introduction of parasites and diseases, special care should be taken to prevent such introductions. Therefore, these exotic species may have a negative impact on native fish populations in Iran through competition, habitat changes, and introduction of parasites and diseases (Esmaeili et al., 2010; 2014; 2017).

It can be concluded that ornamental fishes cannot be considered as one of the main challenges for native ichthyodiversity in Iran, because of their limited introductions and limited suitable habitats. As discussed though, some livebearers and a cichlid have produced established populations in some limited areas. Any eradication programs of exotic fishes have to be accompanied by public awareness campaigns to ensure that the aquarium trade and hobbyists do not release these pet fishes into natural habitats.

\section{Acknowledgment}

I thank the anonymous reviewers for their careful reading of my manuscript and their valuable comments and suggestions.

\section{References}

Coad, B. W. (1996). Exotic fish species in the Tigris-Euphrates basin. Zoology in the Middle East, 13 (1): 71-84. https://doi.org/10.1080/09397140.1996.10637707

Copp, G. H., Bianco, P. G., Bogutskaya, N. G., Erős, T., Falka, I., Ferreira, M. T., Fox, M. G., Freyhof, J., Gozlan, R. E., Grabowska, J., Kováč, V., Moreno-Amich, R., Naseka, A. M., Peňáz, M., Povz, M., Przybylski, M., Robillard, M., Russell, I. C., Stakėnas, S., Šumer, S., Vila-Gispert, A. and Wiesner, C. (2005). To be, or not to be, a non-native freshwater fish? Journal of Applied Ichthyology, 21 (4): 242-262. https://doi.org/10.1111/j.14390426.2005.00690.x

Esmaeili, H. R., Gholamifard, A., Sayyadzadeh, G., Parsi, B., Mirghiasi, S. and Ghasemian, S. (2013). New record of the convict cichlid, Amatitlania nigrofasciata (Gunther, 1867), from the Middle East (Actinopterygii: Cichlidae). Aqua: International Journal of Ichthyology, 19 (4): 225-229.

Esmaeili, H. R., Gholamifard, A., Teimori, A., Baghbani, S. and Coad, B. W. (2010). Xiphophorus hellerii Heckel, 1848 (Cyprinodontiformes, Poeciliidae), a newly introduced fish recorded from natural freshwaters of Iran. Journal of Applied Ichthyology, 26 (6): 937-938. https://doi.org/10.1111/j.1439-0426.2010.01515.x

Esmaeili, H. R., Masoudi, M., Amini Chermahini, M., Esmaeili, A. H., Zarei, F. and Ebrahimi, M. (2017). Invasion of the Neotropical and Nearctic fishes to Iran. FishTaxa, 2 (3): 126-133.

Esmaeili, H. R., Sayyadzadeh, G., Eagderi, S. and Abbasi, K. (2018). Checklist of freshwater fishes of Iran. FishTaxa, 3 (3): 1-95.

Esmaeili, H. R., Teimori, A. and Gholamhosseini, G. (2007). Freshwater ichthyodiversity and its conservation in Iran. XII European Congress on Ichthyology, Cavata (Dubrovnik), Croatia, pp. 200-201.

Esmaeili, H. R., Teimori, A., Owfi, F., Abbasi, K. and Coad, B. W. (2014). Alien and invasive freshwater fish species in Iran: diversity, environmental impacts and management. Iranian Journal of Ichthyology, 1 (2): 61-72. 
Faghani-Langroudi, H., Esmailpour-Chokami, H., Rohani-Rad, M. and Mousavi-Sabet, H. (2014). Sex reversal, mortality rate and growth performance of platy Xiphophorus variatus (Poeciliidae) treated by methyltestosterone. Poeciliid Research, 4 (1): 6-12.

Jouladeh-Roudbar, A., Vatandoust, S., Eagderi, S., Jafari-Kenari, S. and Mousavi-Sabet, H. (2015). Freshwater fishes of Iran; an updated checklist. AACL Bioflux, 8 (6): 855-909.

Khiabani, A., Anvarifar, H. and Mousavi-Sabet, H. (2016). Effect of dietary administration of methyltestosterone and vitamin $\mathrm{C}$ on the sex reversal and survival of Xiphophorus maculatus (Cyprinodontiformes: Poeciliidae). Poeciliid Research, 6 (1): 16-24.

Moshayedi, F., Eagderi, S., Jalili, P. and Mousavi-Sabet, H. (2015a). Allometric growth pattern and morphological development of sailfin molly Poecilia latipinna (Cyprinodontiformes, Poeciliidae) during early development. Poeciliid Research, 5 (1): $1-7$.

Moshayedi, F., Eagderi, S., Parsazade, F., Azimi, H. and Mousavi-Sabet, H. (2015b). Allometric growth pattern of the swordtail - Xiphophorus helleri (Cyprinodontiformes, Poeciliidae) during early development. Poeciliid Research, 5 (1): 18-23.

Mousavi-Sabet, H. (2018). Range extension of an exotic sailfin molly Poecilia latipinna (Lesueur, 1821) in Iran. Poeciliid Research, 8 (1): 18-23.

Mousavi-Sabet, H., Azimi, H., Eagderi, S., Bozorgi, S. and Mahallatipour, B. (2014). Growth and morphological development of guppy Poecilia reticulata (Cyprinodontiformes, Poeciliidae) larvae. Poeciliid Research, 4 (1): 24-30.

Mousavi-Sabet, H. and Eagderi, S. (2014). First record of Poecilia reticulata Peters, 1859 (Cyprinodontiformes, Poeciliidae) from natural freshwaters of Iran. Poeciliid Research, 4 (1): 19-23.

Mousavi-Sabet, H. and Eagderi, S. (2016). First record of the convict cichlid, Amatitlania nigrofasciata (Günther, 1867) (Teleostei: Cichlidae) from the Namak Lake basin, Iran. Iranian Journal of Ichthyology, 3 (1): 25-30.

Mousavi-Sabet, H., Eagderi, S., Moshayedi, F. and Jalili, P. (2015). The effects of supplemental ascorbic acid and unsaturated fatty acids in enriched Artemia on growth performance and stress resistance of sailfin molly fry, Poecilia latipinna. Poeciliid Research, 5 (1): 31-38.

Mousavi-Sabet, H. and Ghasemnezhad, H. (2013). Masculinization, mortality and growth rates of swordtail Xiphophorus hellerii (Poeciliidae) affected by methyltestosterone. Poeciliid Research, 3 (1): 7-13.

Mousavi-Sabet, H., Ghasemnezhad, H. and Petrescu-Mag, I. V. (2013). Effects of diet containing enriched Artemia with unsaturated fatty acids and vitamin C on growth, survival and stress resistance of swordtail Xiphophorus hellerii fry. Poeciliid Research, 3 (1): 14-21.

Mousavi-Sabet, H., Langroudi, H. F. and RohaniRad, M. (2012). Sex reversal, mortality rate and growth of guppy (Poecilia reticulata) affected by 17-alpha methyltestosterone. Poeciliid Research, 2 (1): 1-8.

Mousavi-Sabet, H., Vatandoust, S. and Bleher, H. (2018). An updated checklist of fishes from the Iranian portion of the Harirud/Tedzhen River basin. Aqua: International Journal of Ichthyology, 24 (4): 167-184.

Moyle, P. B. (2002). Inland fishes of California. First Edition. University of California Press, Berkeley and Los Angeles, California, USA. 517 pp.

Nelson, J. S. (2006). Fishes of the world. Fourth Edition. John Wiley and Sons, Inc., Hoboken, New Jersey, USA. 624 pp. 
Nunes, A. L., Tricarico, E., Panov, V. E., Cardoso, A. C. and Katsanevakis, S. (2015). Pathways and gateways of freshwater invasions in Europe. Aquatic Invasions, 10 (4): 359-370. http://dx.doi.org/10.3391/ai.2015.10.4.01

Radkhah, A., Eagderi, S. and Mousavi-Sabet, H. (2016). First record of the exotic species Hemiculter leucisculus (Pisces: Cyprinidae) in southern Iran. Limnetica, 35 (1): 175-178. https://doi.org/10.23818/limn.35.14

Rixon, C. A. M., Duggan, I. C., Bergeron, N. M. N., Ricciardi, A. and Macisaac, H. J. (2005). Invasion risks posed by the aquarium trade and live fish markets on the Laurentian Great Lakes. Biodiversity and Conservation, 14 (6): 1365-1381. https://doi.org/10.1007/s10531 -004-9663-9 